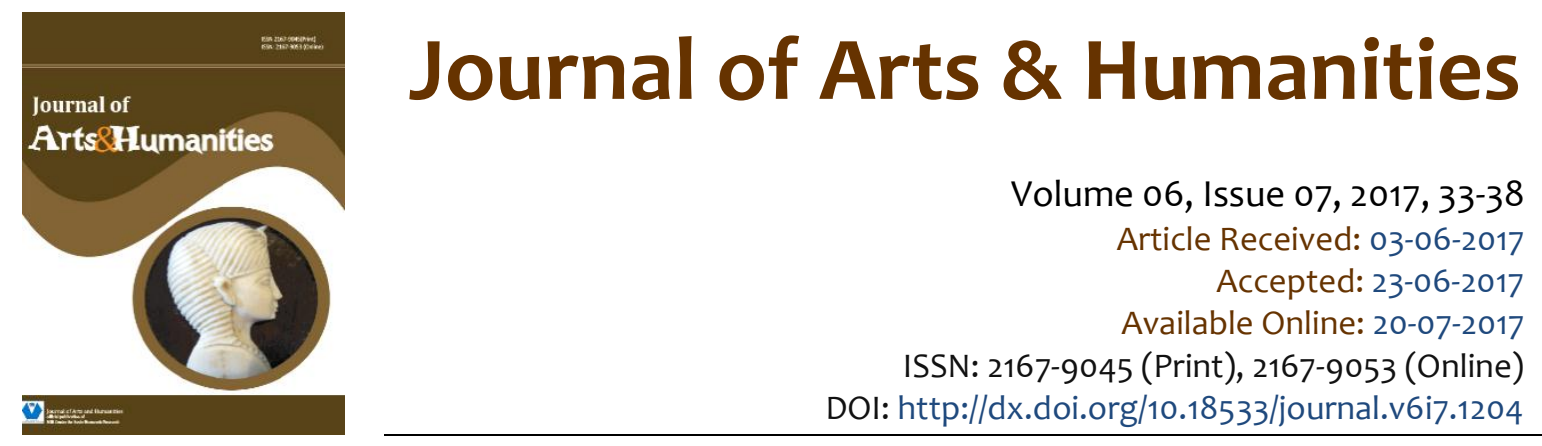

\title{
Anatomy of Gaudi's Curve Architectural Language
}

\author{
Jing Jing Liu', Yue $\mathrm{Hu}^{2}$
}

\begin{abstract}
Gaudi was a unique architectural designer at the aspect of architectural design in Art Nouveau. His architectural design has a unique line design, including the external shape curve of Casa Mila being representative. The external shape design of Casa Mila had subverted the external design of traditional architectures. The wave shape of its vertical wall had broken the contemporary traditional aesthetic consciousness of architectures. Thus, the reasons and effects for the curved shape in the external shape design of Casa Mila showing incisively and vividly how subversive and disruptive Casa Mila being are the source of studying its external curve design. During the same period, many architectural designs were also applied to curves in the external shape of the buildings. Therefore, the external shape of curves on Casa Mila is how its architectural design curves standing out are contrasted by curve design applied to other contemporaneous architectures in the period of Art Nouveau. The view of this paper expounds the reason that the curvilinear design of Casa Mila is different from that of other architectures, and the influence of the curvilinear design of Casa Mila in the period of Art Nouveau. This paper starts with the analysis of the architectural curve of Casa Mila. By comparative analysis of curve profile and its curvature in external modeling of "House of the People" and Tassel Hotel, this paper reveals that Gaudi's architectural features have an unique external modeling and conveys that the architectural curve of external shape more abounds in using natural elements of imitation.
\end{abstract}

Keywords: Casa Mila, Gaudi, Natural Elements, Organic Curve.

This is an open access article under Creative Commons Attribution 4.0 License.

\section{Introduction}

As early as ancient Greek architecture, architects began to use the curve. What the lonic order has decorative sculpture on the stigma shows that curve application uninterrupted constructions in the later. Antoni Gaudi not only used the curve on the decoration of the building but also used the curve in the whole building. It is said that he is the pioneer of the organic curve revolution in the modern architectural design movement.

\footnotetext{
${ }^{1}$ Shanghai University of Engineering Science, Shanghai, 201620, China. E-mail: Huyue2006_1@126.com

${ }^{2}$ Shanghai University of Engineering Science, Shanghai, 201620, China.
} 
This paper mainly analyzes the curve shape and expression from the exterior walls of Casa Mila designed by Gaudi. The exterior walls of Casa Mila show a unique curve design. There is no place of founder rectangle, which the roof of Casa Mila strewn at random, the wall surface of the building is uneven, and the winding fluctuant curve is everywhere (Zhiming, 2006). The exterior shape of Casa Mila's curve design originates from nature. Winding fluctuant wave shapes of walls are often compared to the sea (Yinghua, 2011). The curve design of such natural form is representative in the period of Art Nouveau and the obviously contrast of the curve language analyzing in architectural design in the same period. Thus, Gaudi uses breakthrough architectural techniques for exterior walls of the apartment, his curved language preferring to the natural form.

\section{Organic curves form of Casa Mila}

\subsection{Curve resources of Gaudi's architecture}

Gaudi perfectly using the curve in the construction express his inspiration of architectural design. Gaudi's architectural design is not the curve expression of the organic form at the start. His early style was deeply affected by the culture and customs in Catalonia region. Gaudi's early works: Casa Vicens. (Figure 1) The whole building lines are straight and long. Wrought iron fences in the form of organic curve with the shape of plants give people the sense of high and low cross. For the time being, Gaudi had not been much fascinated by the abstract curve due to be with experience in designing the park decorated with railings and park falls in Barcelona Castle Park and assisting in the design of wrought iron decoration in Bonner Market. Hence, he would have a decoration of wrought iron fence at Casa Vicens on the performance of becoming adept.

What Gaudi designed Palau Güell for Eusebi Güell turned point in more abounding in the creative use of the curve. At that time, European countries were affected by Art Nouveau. Spain also was affected by Art Nouveau advocated "return to nature" infection. So he tried this new thing with his unique design sense. In the middle age of Gaudi, he formed a unique personal style. At this time, his architecture was no longer bound by the same period of architectural design style, but also he had surrealism characteristics, with a certain vanguard. Casa Mila was one of the typical representative in the mature period of Gaudi's design because he would show the curve in Casa Mila incisively and vividly.

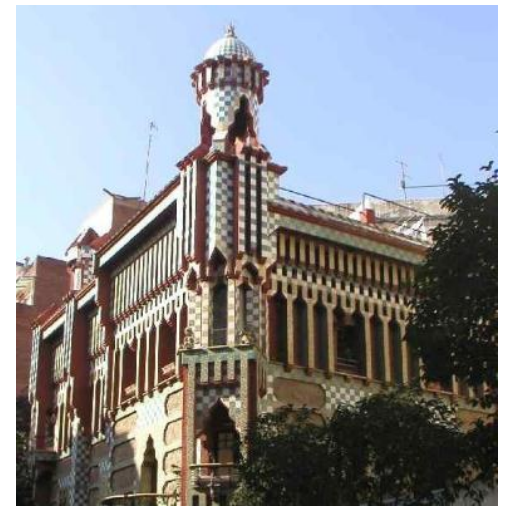

Figure 1: Gaudi's Casa Vicens

\subsection{The expression of curves in Casa Mila}

Gaudi design Casa Mila combined with the naturalistic elements. He was inspired by the undulating shape of mountain chain of Montserrat mountain and Cole Laura hill nearby Barcelona area as it reflected that Gaudi in his young age once recounted art philosophy in his diary:" Art must come from the nature, just for the nature has created the most unique charming."

The building exterior modeling of Casa Mila is processed into a series of strewn at random curve modeling ups and downs along the horizontal direction, which shaped like waves in the sea. Its free open plane freely spread around a courtyard in the ups and downs and in a coherent flow, organic bending or leaning in different degrees in all the partition of different directions, continuous kinking wall and ground into an organic whole, forming curve produced light feeling and decorous feeling by the combination of colorful mosaic materials such as the rubble terra-cotta tiles and broken glass ceramics (Haoyuan, 2011). The whole building with soft sculpture characteristic seen from the appearance, is the typical representative works with thoroughly the performance of organic curves in Art Nouveau. 


\section{External shape curve contrasted by Casa Mila, "House of the People" and Tassel hotel}

\subsection{External shape curve contrasted by Casa Mila and "House of the People"}

However, the expression of Gaudi's architectural curve language is not the first. "House of the People" is designed by Horta in Brussels. (Figure 2) He made use of stone, iron, glass and Belgian brick with matching the external shape of the building as the concave contour of the rules curve, which was also the typical characteristics of his architectural design. The outside shape of Casa Mila produced the curve contour of the general curve of the wave type like sea waves. (Figure 3) The internal shape of its curve is applied from different kinds of animals and plants in nature. It can be said that the curve of the organic form of Casa Mila makes Gaudi's design more inclined to naturalization.

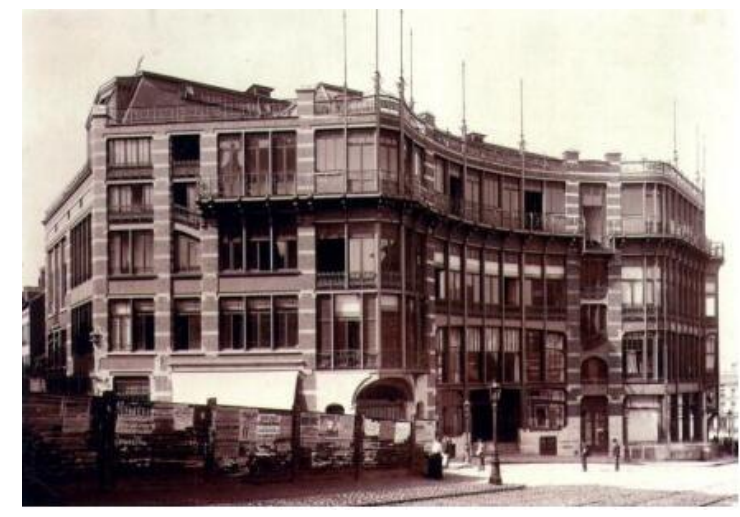

Figure 2: "House of the People" in Brussels

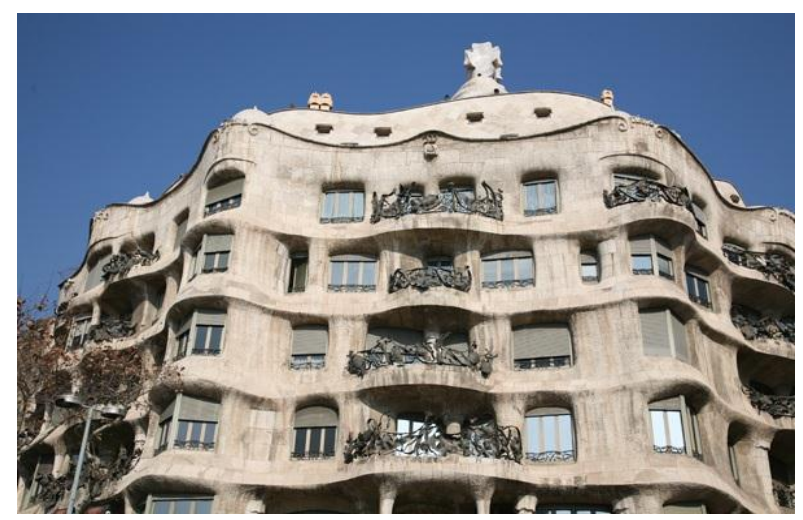

Figure 3: Casa Mila

The designers of the two buildings are influenced by Art Nouveau and their design styles are mature and stable, and it is similar to apply the shape of the curve on the external contour of the building. From the external shape of the curve outline of two buildings eliciting contrast figure (Figure 4): "House of the People" in Brussels basically using geometrical curve, Casa Mila using wave type curve. The wave type curve of the external shape of Casa Mila is irregular and it is difficult to describe its external shape with geometric figure. In contrast, the geometric shape of the curve of "House of the People" in Brussels has a rule, which the basic geometry can be used to describe its external shape. From the view of curvature, the curvature of the wave type curve is more variable than that of the geometric curve. The exterior surface of the building in Brussels is made up of the geometric curve, and its
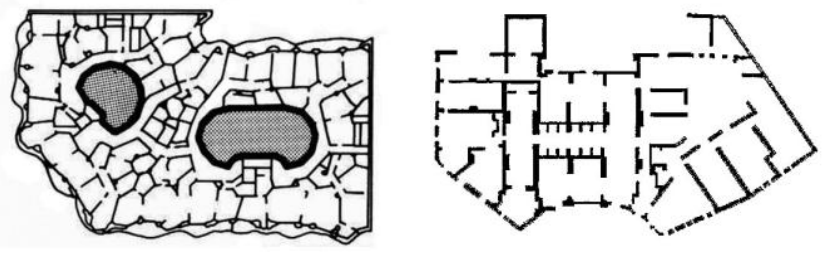

Figure 4: Casa Mila and "House of the People" in Brussels Contrast figure of curve contour in the external shape of building

curvature basically does not have a large change; the exterior surface of Casa Mila formed by the curvature of the wave type curve is the most changeful and unpredicted table. Robert Palmer wrote in (Anthony Gaudi):"Gaudi's naturalism is not produced in the organic shape appearance imitation, but is produced in the laws of their intuition." Judging by the contrast figure of the external surface of two apartments, Casa Mila reveals that builders interpretation of nature permeated through the whole building. However, "House of the People" in Brussels compared with other constructions has a prominent external change of the construction in the same period, but what it makes a comparison with Casa Mila concludes that the understanding of natural elements on his architectural exterior shape design is less deeply than Gaudi's understanding.

\subsection{External shape curve contrast by Casa Mila and Tassel hotel}

Gaudi once said, "Only a madman would try to describe something that does not exist in the world!" Casa Mila, whether from the exterior walls of the building, the roof, the eaves, or the space and 
decoration of apartment interior, is applied to the curve in nature and its performance is not in line with the traditional European architectures and even beyond the traditional ones.

Tassel Hotel is more typical architecture in Art Nouveau, which its characteristic of the internal and external structure of the construction is relatively simple. The exterior styling of Tassel hotel is mainly in the straight line and the plane. On the contrary, the interior of the hotel is decorated with curves. Staircase handrails are built with a certain radian, and filled with the hook shape of curves in the interior of hotel, which steps is designed into a circular arc shape, and decorative patterns of grounds and walls adopt the source nature of curve image, and the decorative abstract lines are arranged on the edge of the roof angle, even pillars displaying all forms with the curve of the tendrils in nature (Qijun, 2009).

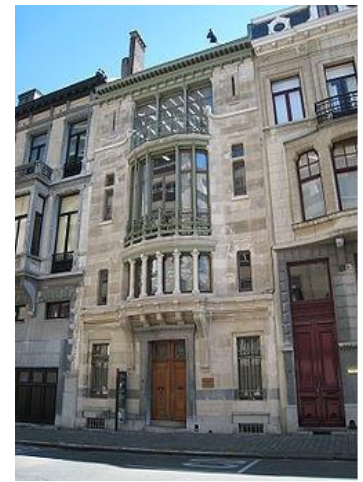

Figure 5: Tassel Hotel
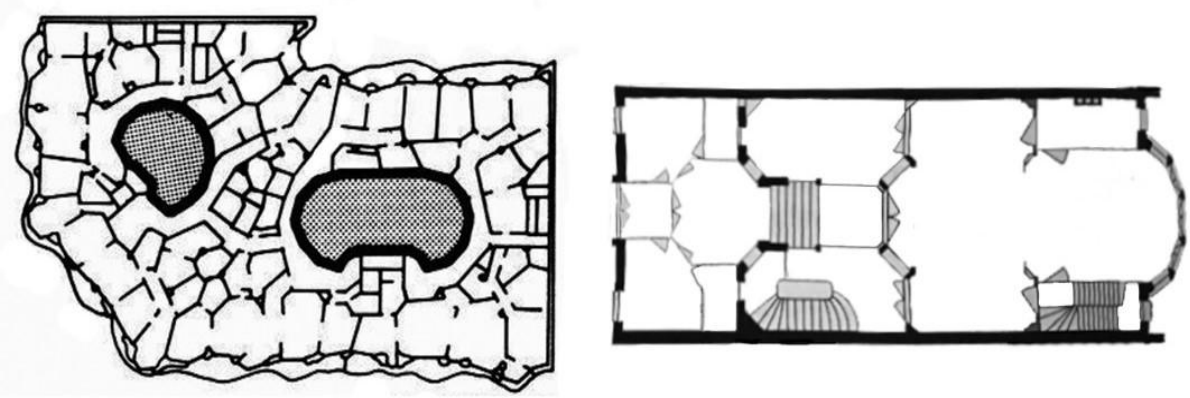

Figure 6: Casa Mila and Tassel Hotel Contrast figure of curve contour in the external shape of building

Horta's Tassel Hotel (Figure 5) and Gaudi's Casa Mila are both constructions in Art Nouveau. Two buildings of designers have their own different views on the application of the curve on the building. Contrast figures of changes in the external shape curve of two constructions (Figure 6): The inspiration of Casa Mila comes from the mountains, plants, animals and other elements in nature, which makes curvatures of the external shape curve of the entire apartment more volatile. The curve modelling elements of Gaudi should be used for the design conception overall building, and imitating nature is used in great quantities in the architectural decoration (Kai, 2011). Instead, the external shape curve of Tassel Hotel is monotony, which makes curvature change monotonous, far less than the curvature of the vine winding shape curve in the interior decoration is complex and changeable. Two buildings from the contrast figures clearly show that if the curvature of the external shape curve of compared with the curvature of Casa Mila, the curvature of Tassel Hotel will be applied to only a part of the facade of Casa Mila. Although Horta's Tassel Hotel inside contains the organic form of curves, but Gaudi using natural elements of the curve imitating design in architectural expression more unique than Horta's from the curve of the overall construction design. Indeed, for application to the curve form extracted from the nature makes that Gaudi will be tied to subsequent organic architecture (Ran, 2014). What he makes the building with the curve of the organic form and utilization and imitation of natural elements let Gaudi become one of the pioneers of the trend toward "organic architecture" in the rise of the occasion. The famous architect Corbusier called him " the pioneer of postmodernism ", from a certain point of view, which he is worthy of it (Yi, 2014).

\section{Conclusion}

The exterior walls of Casa Mila with such subversive curves architectural language come from two aspects. One is that Gaudi uses breakthrough architectural construction on the exterior wall chiseled in the whole building. Another is that Gaudi applies and interprets the form of nature to the architectural curve language on the external walls.

The art style is divided into curve type and straight line type in Art Nouveau. In this period, most of architectural characteristics exert a large number of geometrical lines on the external shape of the construction. What Gaudi's architectural design stands out most of constructions in the same period is 
that his sense of performance using natural elements in the architectural design of the curve is more unique than other people. Casa Mila for Gaudi's representative works in the curvature interpretation and Horta's "House of the People" in the curvature expression in Brussels have the same also have different. Two buildings have curves and curved surfaces composed of exterior forms in common, but it's unusual that the external shape curve of Casa Mila shows coherence changes and different curvature; the external shape curve of "House of the People" in Brussels uses a single curve and little change in the curvature.

From the view of point of curvature comparison of the curve design of Casa Mila and the curve expression of Horta's another building, Tassel Hotel, Gaudi varied frequently with the curvature of the curve from interior to exterior in the architectural design, by contrast, Tassel Hotel's curvature variation of architectural design curve can be presented in the interior design of the classic "Belgian line". Compared Tassel Hotel's whole external shape curve in multiple variety with Casa Mila's, its external shape curve changes in the part not from the overall change.

From a comparative analysis of the external form of Casa Mila, "House of the People" in Brussels and Tassel Hotel, three buildings are architectures in the period of Art Nouveau, and their common in the building is in the concept of embodiment in Art Nouveau. Casa Mila's external shape curve is more unique than the other two buildings, which is not separated from the concept of architectural designers, which shows that Gaudi's design concept in the application of natural elements is unique. Gaudi's design is influenced by animals, plants and even sea waves in nature, so his architectural design has an organic form of curves. However, Horta architectural design is under the influence of his teacher Alphonse Barratt's neoclassical, so a large number of the external shape of constructions are relatively simple so that the curve is also more used by the geometric curve. He is involved in the organic form of the curve, more imitating tendrils dendrite of nature in the interior of the building modelling, and combining spiral curve. It can be said that curvature variation in the external shape curve of Casa Mila completely derived from nature combines with Gaudi 's architectural design of personal philosophy so that the external shape of Casa Mila shows the characteristic of soft sculpture.

On the other hand, the features of the architectural structure determine different characteristics of the external curve of Casa Mila and other two buildings in the interpretation. The building structure of the apartment is wave ring structure seen from the ichnography of Casa Mila, therefore, weight of the whole building is supported by pillars. Apart from this, the exterior wall of the whole building is elaborately chiseled through stones. For this reason, the exterior shape curve of the apartment is changeable and abundant without too much geometric type of curvature value because the exterior wall and the inner wall of the apartment are not limited by weight. The obvious geometry of the building structure can be seen from ichnographies of "House of the People" in Brussels and Tassel Hotel, so using the external shape curve of the two building is limited, and their curvature variations are limited in the meantime.

In other words, the architectural designer's personal philosophy and the unique structure of constructions make the whole building out of the ordinary. The external shape curve of Casa Mila is influenced by the impact of Art Nouveau on Gaudi and by his love of nature. For this reason, it has the wave type of unique shape and unique curve. The apartment is also affected by the unique annularity of building structure, showing the unique curvature of the external curve, which makes the whole apartment in a large number of buildings in period of Art Nouveau abounding more in characteristics of natural elements and possessing more features. Hence, Casa Mila is a naturalized and unique architecture with Gaudi's naturalism and wave annularity of building structure.

\section{References}

Chen ran, Wang shouzhi. Exploring Gaudi's curve consciousness from Casa Mila [J]. Art education, 2014, (11): 241-242.

Fang yi. History of world modern design [M].Beijing: Posts \& telecom press, 2014. 
Guo zhiming. The rational and irrational thinking of Gaudi architectural design from Casa Mila [J]. Sichuan Architectural, 2006, 26 (z1):77-79.

Ma haoyuan, Yuan tao. The new enlightenment of Chinese modern architecture from the architectural aesthetics of Casa Mila [J]. China Market, 2011（32）: 48-50.

Shao yinghua, Tong baisong. The rational mind the romantic realization-irrational analysis of Gaudi's Casa Mila [J]. Management \& Technolosy of SME periodical, 2011 (13):70-71.

Wang qijun. A hand book of world architecture [M].Beijing: China machine press, 2009.

Zong kai. The beauty of Gaudi's architecture from the perspective of contemporary aesthetics -- a review of the embodiment and significance of Gaudi's architecture in the modern architectural aesthetics [J]. Sichuan Architectural, 2011, 31(6):78-80. 